\title{
Research Paper: Comparison of Upper Limb Disability in Overhead Women Athletes of Handball, Volleyball, Softball, and Swimming
}

\author{
Elmira Arabi $^{1^{*}}$ (D), Gholam Hossein Nazemzadegan² (D)
}

1. Department of Health and Sport Medicine, Faculty of Physical Education and Sport Sciences, University of Tehran, Tehran, Iran.

2. Department of Motor Behavior, Faculty of Education and Psychology, University of Shiraz, Shiraz, Iran.

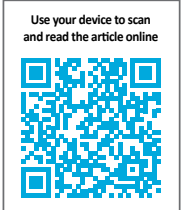

Citation Arabi E, Nazemzadegan GH. Comparison of Upper Limb Disability in Overhead Women Athletes of Handball, Volleyball, Softball, and Swimming. Physical Treatments. 2021; 11(2):103-110. http://dx.doi.org/10.32598/ptj.11.2.446.2

: http://dx.doi.org/10.32598/ptj.11.2.446.2

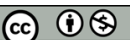

Article info:

Received: 18 Jul 2020

Accepted: 23 Jan 2021

Available Online: 01 Apr 2021

Keywords:

Disability, Upper limb, Elite, Women, Overhead sports

\begin{abstract}
A B S T R A C T
Purpose: The shoulder joint is one of the most commonly injured joints in sports and may lead to disability, especially in the upper extremities of overhead players (handball, volleyball, softball, and swimming).

Methods: This research is a causal-comparative study. After the approval of the Ethics Committee of the Medical University of Tehran, this study was conducted on 120 overhead athletes (Mean \pm SD height: $1.69 \pm 0.07 \mathrm{~m}, \mathrm{Mean} \pm \mathrm{SD}$ weight: $63.54 \pm 7.79 \mathrm{~kg}$, Mean $\pm \mathrm{SD}$ age: $21.96 \pm 2.94$ years, Mean \pm SD body mass index: $22.11 \pm 2.32 \mathrm{~kg} / \mathrm{m}^{2}$ ). The inclusion criteria were elite female players in overhead sports with at least three years of experience in one of these sports (handball, volleyball, softball, and swimming). Samples with a history of surgery or cervical nerve problems, fractures in the shoulder area, and inflammatory joint disease were excluded from the study. The demographic information was obtained through a researcher-made questionnaire, and the Disabilities of the Arm, Shoulder and Hand (DASH) Questionnaire was used to measure the degree of upper limb disability in daily activities.
\end{abstract}

Results: In comparison between the study groups, a significant difference was observed between the dependent variable (DASH) and the research groups $(\mathrm{F}=6.067, \mathrm{df}=3, \mathrm{P}=0.002, \mathrm{Eta}=0.342$ ). Using the Bonferroni post hoc tests, the difference between volleyball and softball $(\mathrm{P}=0.44)$, volleyball and swimming $(\mathrm{P}=0.009)$, and handball and swimming players $(\mathrm{P}=0.022)$ were reported. In the next step, BMI characteristics, weekly training hours, and the number of training sessions per week were entered into the data analysis process as covariate variables $(\mathrm{F}=8.099$, $\mathrm{df}=0.3, \mathrm{P}=0.000$, Eta $=0.432$ ). The Bonferroni post hoc test indicates the difference between volleyball and swimming athletes $(\mathrm{P}=0.001)$ and handball and swimming $(\mathrm{P}=0.002)$.

Conclusion: The present study results indicate a high rate of upper limb disability in elite women athletes. The present study results showed no difference between volleyball and handball due to the nature of these two disciplines and handball, softball, and swimming.

\section{"Corresponding Author:}

Elmira Arabi, MA.

Address: Department of Health and Sport Medicine, Faculty of Physical Education and Sport Sciences, University of Tehran, Tehran, Iran. Phone: +98 (917) 5270273

E-mail: erabi.elmira@yahoo.com 


\section{Highlights}

- The high rate of upper disabilities in elite women athletes;

- The relationship between characteristics such as BMI, weekly training, and number of training sessions per week with upper limb disability in elite women athletes in various sports;

- The relationship between sports and the degree of inability to perform daily tasks;

- The importance of the shoulder joint in volleyball, handball, softball, and swimming.

\section{Plain Language Summary}

The shoulder joint plays an important role in upper limb mobility. Repeated movements from the top of the head stress the shoulder joint and disrupt the stability of the shoulder joint, which causes pain in the shoulder joint. If left untreated, instability and pain over time can lead to upper limb disability. The causes of upper limb disability are related to the sport and are of great importance due to the athlete's disability and high medical costs. This problem may lead to early retirement in athletes. Due to their nature, they are among the sports in which upper limb disability is related to the field has a high prevalence. Due to the importance of upper limb disability, it is necessary to compare the disability in athletes of the desired disciplines. A total of 120 athletes in the fields of volleyball, handball, softball, and swimming active in the Premier League and national teams were examined in this study. The athletes had a high rate of overhead movements, the results showed that the severity of disability in athletes above the head and there was a significant difference between the fields in the study and also the characteristics of BMI, training hours, and the number of training sessions per week. There was a significant difference between athletes of different fields.

\section{Introduction}

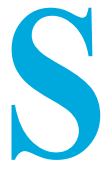

houlder injuries are among the most common injuries seen in various sports [1]. However, it is difficult to determine the exact percentage of these injuries that result from a stroke or repetitive overexertion. But it seems reasonable that many of these injuries are due to repetitive overexertion. Hyperthermia injuries after microtrauma are caused by additional loads on the joints and have significant effects on the quality of life $[2,3]$. The prevalence of shoulder pain is reported to be $30 \%$ to $45 \%$ among athletes who use overhead movements (volleyball, handball, softball, and swimming) [4]. Also, the shoulder joint in overhead athletes is known as the art of movement; its high range of motion plays an essential role in the mobility of the upper limbs $[5,6]$. Performing repetitive movements during sports activities, especially throwing movements over the head, in volleyball, handball, softball, swimming, and other sports, exerts stress on the shoulder joint and impairs its stability, and causes pain in the shoulder $[7,8]$. This instability and pain in the shoulder joint also affect muscle strength. Proper strength as one of the most important factors in the optimal performance of daily life activities reduces the risk of vulnerability in athletes [9].
Failure to properly treat and rehabilitate injuries caused by overuse can lead to disability in the upper limbs of overhead athletes over time.

Athletes in the field of study have a high rate of overhead movements. In volleyball, many skills, such as spike, serve and defense on the net, require constant contact of the athlete's upper limb with the ball in the overhead position [10]. Performing handball techniques, power throws, and speed above the head occurs a lot. Therefore, the joints of the shoulder girdle and its muscles are constantly exposed to extreme forces [11]. Another sport is softball, in which athletes use throwing to move the ball instead of hitting. It requires a wide range of shoulder movement, strength, and power. All softball techniques require the ability to perform the lifting phase during the throw mechanics [12].

Another sport studied was swimming. Along with the increasing popularity of swimming, the unstable structure of the shoulder girdle and the excessive pressure applied to this joint during repeated blows have made shoulder injuries the most common complaint in swimmers [13]. These factors can be common causes of upper limb disability and are of great importance due to their 
damages and high medical costs [14]. This problem may lead to early retirement in athletes [15].

The overhead sports are among the sports in which the disability of the upper limbs is highly prevalent. Due to the seriousness of upper limb disability, it is necessary to compare disability in athletes of the mentioned sports. According to the hypotheses, research to compare disability in overhead athletes seems necessary. Therefore, this study aimed first to compare upper limb disability in volleyball, handball, softball, and swimming players and then to determine the relationship between their characteristics, including Body Mass Index (BMI), weekly training hours, and the number of weekly training sessions with upper limb disability in elite women overhead athletes. In order to identify the effect of these variables on the disability of athletes' upper limbs. According to a study conducted on adolescents with shoulder pain, the results showed that people with shoulder pain had reduced upper limb function in daily activities and sports skills. Inattention to the shoulder joint problems limits many body activities, especially the upper limbs [16].

\section{Materials and Methods}

The present study is a causal-comparative study. The study sample comprised 120 female athletes in the fields of volleyball, handball, softball, and swimming who were active in the Premier League and national teams. They were selected by the available sampling method. The inclusion criteria were elite female players with at least three years of experience in one of these sports. The samples with a history of surgery or cervical nerve problems, shoulder fractures, and inflammatory joint diseases were excluded from the study. Initially, the researcher was allowed to work with the Code of Ethics of IR.UT.SPORT.REC.1398.004. Then, for the selection of individuals, the consent form and personal information were provided to the subjects and verbal information about the level of activity of individuals and their willingness to participate in the research was provided. They were also assured that the obtained information was confidential and they could leave the investigation at any time. Then, after the necessary explanations about the goals and benefits of the present study, a consent form and a personal information questionnaire were provided to those who wished to participate in the research. The present study was a cross-sectional descriptive study. The study data were collected through interviews and various questionnaires. A researcher-made questionnaire was used to obtain personal information and sports records. Several physical education experts have measured the validity and reliability of this questionnaire, and the ICC of the questionnaire is 91\% [17].
Shoulder dysfunction was assessed by the Disability of the Arm, Shoulder, and Hand (DASH) questionnaire. It was measured one week before the study. This questionnaire includes questions to assess the level of difficulty in performing daily tasks (21 questions), pain intensity during sleep and activity, joint stiffness (5 questions), and the effect of the upper limb on social activities and work (4 questions). To use the results of the questionnaire, the person must answer at least 27 questions out of 30 questions. The score of this questionnaire is calculated from 100, and to calculate the final score after adding the score of each question and taking their average, the result is subtracted by one and then multiplied by 25 . The higher the number and closer to 100 , the greater the "disability" of the person $[18,19]$. The validity of the DASH questionnaire for different questions is between $80 \%$ and $70 \%$, and its reliability is $96 \%$ [20]. In the present study, a Persian version of the DASH questionnaire was used. Finally, after collecting these data, the characteristics of the subjects, such as age, height, and weight, along with the research variables, were analyzed in two sections of descriptive and inferential statistics in SPSS version 24. The DASH results were used to compare overweight athletes. Also, the significance level should be considered smaller or equal to 0.50 throughout the research.

\section{Results}

To describe the research groups, the variables of age, weight, height, and BMI were calculated based on descriptive indicators related to these variables. Table 1 presents the results. Table 2 presents the average severity of shoulder disability in the research samples by different sports.

According to the results reported in comparison between groups of different sports, a significant difference was observed between the dependent variable (DASH), $(\mathrm{F}=6 / 067)$ and degree of freedom $(\mathrm{df}=3)$, level of significance $(\mathrm{P}=0.002)$ and coefficient. Eta $(\mathrm{Eta}=0.342)$ is reported (Table 3 ).

Using the Bonferroni post hoc test, the difference between volleyball and softball $(\mathrm{P}=0.044)$, volleyball and swimming $(\mathrm{P}=0.009)$, handball, and swimming ( $\mathrm{P}=0.022)$ is confirmed and according to the reported results. There was no significant difference between volleyball and handball. This similarity can be related to the similar nature of these two sports. Also, the difference between these two sports with other overhead sports can be seen with softball, which is a racquet game, and swimming which has a different form. The present study results showed that volleyball players have some degree of functional disability in the upper limb. There 
Table 1. Demographic characteristics of players

\begin{tabular}{cccc}
\hline Variables & Max & Min & Mean \pm SD \\
\hline Age $(\mathrm{y})$ & 28 & 18 & $21.96 \pm 2.94$ \\
\hline Weight $(\mathrm{kg})$ & 78 & 47 & $63.54 \pm 7.79$ \\
\hline Height $(\mathrm{m})$ & 1.92 & 1.53 & $1.69 \pm 0.07$ \\
\hline Body mass index $\left(\mathrm{kg} / \mathrm{m}^{2}\right)$ & 26.36 & 17.16 & $22.11 \pm 2.32$ \\
\hline
\end{tabular}

PHYSICAL TREA $\$ MENTS

Table 2. The severity of disability in different sports

\begin{tabular}{ccc}
\hline String Type (M) & Mean \pm SD & No. \\
\hline Volleyball & $20.83 \pm 9.01$ & 11 \\
\hline Handball & $20.57 \pm 6.55$ & 8 \\
\hline Softball & $13.25 \pm 4.67$ & 12 \\
\hline Swimming & $10.61 \pm 3.21$ & 8 \\
\hline
\end{tabular}

PHYSICAL TREA $\ M E N T S$

was a significant difference between the level of functional disability in volleyball players compared to other overhead sports (softball and swimming). No significant difference was observed between volleyball and handball players (Table 4 ).

In the next step, BMI, weekly training hours, and the number of training sessions per week were entered into

Table 3. DASH dependent variable in different sports groups

\begin{tabular}{ccccc}
\hline DASH & df & F & P & Eta \\
\hline Sports groups & 3 & 6.067 & 0.002 & 0.342 \\
\hline
\end{tabular}

PHYSICAL TREA $\$ MENTS

Table 4. Comparison of results between groups

\begin{tabular}{|c|c|c|c|c|c|}
\hline \multirow{2}{*}{ First Group } & \multirow{2}{*}{ Second Group } & \multirow{2}{*}{ Mean Difference } & \multirow{2}{*}{$\mathbf{P}$} & \multicolumn{2}{|c|}{ Mean Difference (95\% Confidence Interval) } \\
\hline & & & & Lower Bound & Upper Bound \\
\hline \multirow{3}{*}{ Volleyball } & Softball & 7.584 & 0.044 & 0.131 & 15.037 \\
\hline & Swimming & 10.215 & 0.009 & 1.919 & 18.511 \\
\hline & Handball & 0.261 & 1.000 & -8.035 & 8.557 \\
\hline \multirow{3}{*}{ Handball } & Swimming & 9.954 & 0.022 & 1.026 & 18.881 \\
\hline & & & & & \\
\hline & Softball & 7.323 & 0.100 & -0.827 & 15.472 \\
\hline Softball & Swimming & 2.631 & 1.00 & -5.518 & 10.781 \\
\hline
\end{tabular}

PHYSICAL TREA $\ M E N T S$ the data analysis process as covariates. With $\mathrm{df}=3.3$ and $\mathrm{F}=8.099$, the Bonferroni post hoc test results show a difference between volleyball and swimming athletes $(\mathrm{P}=0.001)$ and handball and swimming athletes $(\mathrm{P}=0.002)$. According to the reported results, athletes who had higher BMI and the number of training sessions 
per week, as well as training hours per week, had lower upper extremity functional ability than other athletes.

\section{Discussion}

The statistical results show that the severity of upper limb disability is high in the subjects. However, the present study results showed that in addition to the high severity of upper limb disability, there is a significant difference in the degree of disability between athletes in different overhead disciplines. Because of the high volume of training of professional teams, the intensity of the competition, the short rest intervals between games, and the repetitive and heavy movements that each player must perform continuously during training sessions, one can expect upper limb disability in overhead athletes. The results also showed a difference between BMI and upper limb disability in volleyball and swimming and handball and swimming. Athletes with higher BMI are more likely to have upper limb disability. The findings of the present study suggest such a possibility.

Another significant result of the study was the difference between swimming, handball, and volleyball, as the shoulder injuries that occur in athletes are usually similar, but the type of injury mechanism may be different. Also, there is no significant difference between the disability in volleyball and handball. To justify this finding, we can refer to the level of athletes in both disciplines. Since the athletes in both disciplines in this study were all professional and Premier League athletes and their level of activity were in the same range, it can be expected that the extent of their injuries and consequent disability is almost the same. In this regard, it should be noted that a study that compared the shoulder dysfunction of these two disciplines was not found. Besides, the present study results showed significant difference between handball and softball, which can be due to the mechanism of injury as handball is a high-impact sport and softball is a non-collision sport. The nature of swimming is similar to other overhead disciplines, but swimming is an individual and non-ball sport. Also, the movements used in performing the techniques of this field are different compared to other studied sports. Techniques performed in swimming are performed at a certain distance and time that the upper body muscles are used endurance [21].

Given the hypotheses about the relationship between sports and the degree of inability to perform daily activities, therapists generally prefer to imagine the existence of sports based on such a hypothesis corresponding to the level of disability of the athlete. However, in many cases, it is seen that an athlete, despite being a professional, still has a high level of performance. It is believed that disability is a multidimensional concept that includes objective and subjective factors and considers the individual's understanding of the quality of life in important aspects. Also, individual and social support interventions in dealing with challenging situations can affect a person's perception of the extent of his or her disability [22]. Therefore, in justifying why the high level of athlete in the present study did not cause extensive upper disabilities, it can be assumed that mental factors and efforts to improve quality of life in influencing her inference of her disability. It is suggested that comprehensive research with clinical evaluations be conducted to identify the mechanisms of shoulder injury in various overhead disciplines (watery, Rocket). Non-overhead and non-athletes who have upper extremity disability in daily activities can pave the way for future studies for comparative studies. It is also suggested that this research be conducted in a larger sample that includes men. A review of the sources revealed a lack of higherlevel studies, such as systematic and meta-analytic reviews. So conducting such studies to determine a more explicit structure or system of how the relationship between sport and disability is recommended.

\section{Conclusion}

The shoulder joint is the art of movement that is damaged in repetitive activities of the upper arm and leads to upper limb disability. Volleyball and handball, as well as handball, softball, softball and swimming, there is no upper limb disability, but there is a significant difference between other disciplines due to the nature of the discipline and the mechanism of injury. Depending on the risk factors, the necessary measures can be taken to prevent the occurrence of upper limb disability disorders.

\section{Ethical Considerations}

\section{Compliance with ethical guidelines}

This study was approved by the Ethics Committee of the University of Tehran (https://civilica.com/doc/194235/).

\section{Funding}

This research did not receive any grant from funding agencies in the public, commercial, or non-profit sectors.

\section{Authors' contributions}

Both authors equally contributed to preparing this article. 


\section{Conflict of interest}

The authors declared no conflict of interest.

\section{Acknowledgments}

We would like to thank all the coaches and athletes, and those who helped us in this research.

\section{References}

[1] Zaremski JL, Wasser JG, Vincent HK, Mechanisms and treatments for shoulder injuries in overhead throwing athletes. Current Sports Medicine Reports. 2017; 16(3):179-88. [DOI:10.1249/JSR.0000000000000361] [PMID]

[2] Aguinaldo AL, Buttermore J, Chambers H. Effects of upper trunk rotation on shoulder joint torque among basebal pitchers of various levels. Journal of Applied Biomechanics. 2007; 23(1):42-51. [DOI:10.1123/jab.23.1.42] [PMID]

[3] Herin F, Vézina Vezin M, Thaon I, Soulat J-M, Paris Ch, ESTEV group. Predictors of chronic shoulder pain after 5 years in a working population. Pain. 2012; 153(11):2253-9. [DOI:10.1016/j.pain.2012.07.024] [PMID]

[4] Leão Almeida GP, Silveria PF, Rosseto NP, Barbosa G, Ejnisman B, Cohen M. Glenohumeral range of motion in handball players with and without throwing-related shoulder pain. Journal of Shoulder and Elbow Surgery. 2013; 22(5):602-7. [DOI:10.1016/j.jse.2012.08.027] [PMID]

[5] Itoi E. Pathophysiology and treatment of atraumatic instability of the shoulder. Journal of Orthopaedic Science. 2004 9(2):208-13. [DOI:10.1007/s00776-003-0748-1] [PMID]

[6] Wilk KE, Meister K, Andrews JR. Current concepts in the rehabilitation of the overhead throwing athlete. The American Journal of Sports Medicine. 2002; 30(1):136-51. [DOI:10.1177/03635465020300011201] [PMID]

[7] Kelly SM, Wrightson PA, Meads C. Clinical outcomes of exercise in the management of subacromial impingement syndrome: A systematic review. Clinical Rehabilitation. 2010; 24(2):99-109. [DOI:10.1177/0269215509342336] [PMID]

[8] de Villarreal DESS, Kellis E, Kraemer WJ, Izquierdo M. Determining variables of plyometric training for improving vertical jump height performance: A meta-analysis. The Journal of Strength \& Conditioning Research. 2009; 23(2):495-506. [DOI:10.1519/JSC.0b013e318196b7c6] [PMID]

[9] Ballinger DA, Rintala DH, Hart KA. The relation of shoulder pain and range-of-motion problems to functional limitations, disability, and perceived health of men with spinal cord injury: A multifaceted longitudinal study. Archives of Physical Medicine and Rehabilitation. 2000; 81(12):157581. [DOI:10.1053/apmr.2000.18216] [PMID]
[10] Bonza JE, Fields SK, Yard EE, Comstock D. Shoulder injuries among United States high school athletes during the 2005-2006 and 2006-2007 school years. Journal of Athletic Training. 2009; 44(1):76-83. [DOI:10.4085/1062-605044.1.76] [PMID] [PMCID]

[11] Taha ShA, Ibrahim Akl A-RI, Zayed MA. Electromyographic analysis of selected upper extremity muscles during jump throwing in handball. American Journal of Sports Science. 2015; 3(4):79-84. [DOI:10.11648/j.ajss.20150304.13]

[12] Bogenschutz ED, Smith HD, Warden SJ. Midhumerus adaptation in fast pitch softballers and the impact of throwing mechanics. Medicine and Science in Sports and Exercise. 2011; 43(9):1698-1706. [DOI:10.1249/ MSS.0b013e3182134e4f] [PMID] [PMCID]

[13] Mazloum V. [The comparison of shoulder injuries in dominant and nondominant limbs of the swimmers 2010 (Persian)]. Paper presented at: National Conference of Physical Education and Sports Science Students of Iran 15 December 2011; Tehran, Iran. https://civilica.com/ doc/194235

[14] Rahimi A, Ahmadi F, Akhoond MR. [An investigation into the prevalence of vertebral column pains among the nurses employed in Hamedan Hospitals, 2004 (Persian)] 2004. Razi Journal of Medical Sciences. 2006; 13(51):105-14 http://rjms.iums.ac.ir/article-1-597-fa.htmlhttp:/ / rjms iums.ac.ir/article-1-597-fa.pdf

[15] Trinkoff AM, Lipscomb JA, Geiger-Brown J, Storr CL Brady BA. Perceived physical demands and reported musculoskeletal problems in registered nurses. American Journal of Preventive Medicine. 2003; 24(3):270-5. [DOI:10.1016/S0749-3797(02)00639-6] [PMID]

[16] de Oliveira DVMA, Pitangui ACR, Gomes MRA, da Silva De Silva HA, Dos PassosPassos MHP, de Araújo De Araujo RC. Shoulder pain in adolescent athletes: Prevalence, associated factors and its influence on upper limb function. Brazilian Journal of Physical Therapy. 2017; 21(2):107-13. [DOI:10.1016/j.bjpt.2017.03.005] [PMID] [PMCID]

[17] Mohseni Bandpei MA. Keshavarz R, Minoonejad H Ebrahimi Varkiani M, Samadi H, Latifi S. [Shoulder pain and functional disability in Iranian premier league volleyball players (Persian)]. Journal of Mazandaran University of Medical Sciences. 2012; 22(90):95-103. http://jmums mazums.ac.ir/article-1-1169-en.html

[18] Merolla G, Corona C, Zanoli G, Cerciello S, Giannotti S, Porcellini G. Cross-cultural adaptation and validation of the Italian version of the kerlan-jobe orthopaedic clinic shoulder and elbow score. Journal of Orthopaedics and Traumatology. 2017; 18(4):415-21. [DOI:10.1007/s10195017-0467-6] [PMID] [PMCID]

[19] Themistocleous GS, Goudelis G, Kyrou I, Chloros GD Krokos A, Galanos A, et al. Translation into Greek, crosscultural adaptation and validation of the Disabilities of the Arm, Shoulder, and Hand Questionnaire (DASH). Journal of Hand Therapy. 2006; 19(3):350-7. [DOI:10.1197/j. jht.2006.04.014] [PMID]

[20] Clewley D, Flynn TW , Koppenhaver Sh. Trigger poin dry needling as an adjunct treatment for a patient with adhesive capsulitis of the shoulder. Journal of Orthopaedic \& Sports Physical Therapy. 2014; 44(2):92-101. [DOI:10.2519/ jospt.2014.4915] [PMID] 
[21] Tate A, Turner GN, Knab SE, Jorgensen C, Strittmatter A, Michener LA. Risk factors associated with shoulder pain and disability across the lifespan of competitive swimmers. Journal of Athletic Training. 2012; 47(2):149-58. [DOI:10.4085/1062-6050-47.2.149] [PMID] [PMCID]

[22] Azimi Meibody A, Azimi Meibody J, Bashardoost N. Hoseinzadeh A, Hoseinipanah H, Ataei F. [Evaluation of upper limb disability in pregnant women suffering from carpal tunnel syndrome (Persian)]. Journal of Shahrekord University of Medical Sciences. 2009; 11(1):40-5. http:/ / eprints.skums.ac.ir/id/eprint/5755 
This Page Intentionally Left Blank 